\title{
Acidity Study of Donor-Acceptor Complexes \\ of Boric Acid with Polyols \\ for Oil Displacing Compositions
}

\author{
Vladimir A. Kuvshinov, Lyubov K. Altunina*, \\ Lyubov A. Stasieva and Ivan V. Kuvshinov \\ Institute of Petroleum Chemistry $S B$ RAS \\ 4 Akademichesky, Tomsk, 634055, Russia
}

Received 13.03.2019, received in revised form 21.05.2019, accepted 20.08.2019

The results of theoretical and experimental studies of the acidity of donor-acceptor complexes of boric acid with polyols - glycerol and sorbitol, which were used in the development of oil-displacing compositions, are presented. A model of donor-acceptor acid-base equilibria in coordinating polyol solvents has been created, due to which the constants of polyolboric acids formation and ionization were determined by $\mathrm{pH}$-meter and electrical conductivity methods. The obtained constant values were used to calculate the compositions buffer capacity. Due to the using a mixture of polyolboric acids in the compositions at various ratios it was possible to regulate the range of the buffer action.

Keywords: coordinating solvents, complex compounds, polyolboric acids, polyols, oil recovery, physicochemical methods, oil-displacing chemical compositions, high viscosity oil.

Citation: Kuvshinov V.A., Altunina L.K., Stasieva L.A., Kuvshinov I.V. Acidity study of donor-acceptor complexes of boric acid with polyols for oil displacing compositions, J. Sib. Fed. Univ. Chem., 2019, 12(3), 364-373. DOI: 10.17516/1998-28360133 .

(c) Siberian Federal University. All rights reserved

* Corresponding author E-mail address: alk@ipc.tsc.ru 


\title{
Исследование кислотности
}

\section{донорно-акцепторных комплексов борной кислоты \\ с полиолами для нефтевытесняющих композиций}

\author{
В.А. Кувшинов, Л.К. Алтунина, \\ Л.А. Стасьева, И.В. Кувшинов \\ Институт химии нефти СО РАН (ИХН СО РАН) \\ Россия, 634055, Томск, Академический, 4
}

Приведены результаты теоретических и экспериментальных исследований кислотности донорно-акцепторных комплексов борной кислоты с полиолами - глицерином и сорбитом, которые использованы при разработке нефтевытесняющих композиций. Создана модель донорно-акцепторных кислотно-основных равновесий в координирующих полиольных растворителях, с помощью которой определены константы образования и ионизации полиолборных кислот методами рН-метрии и электропроводности. Полученные значения констант использованы для расчета буферной емкости композииий. Показана возможность регулирования диапазона буферного действия путем использования смеси полиолборных кислот в различных соотношениях.

Ключевые слова: координирующие растворители, комплексные соединения, полиолборные кислоты, полиоль, нефтеотдача, физико-химические методы, нефтевытесняющие химические композиции, высоковязкая нефть.

\section{Введение}

В настоящее время актуальная научно-техническая задача - разработка физикохимических методов увеличения нефтеотдачи залежей тяжелой высоковязкой нефти [1]. Эти залежи размещены преимущественно в карбонатных пластах-коллекторах. Среди физикохимических методов воздействия на карбонатные нефтенасыщенные пласты с целью увеличения степени извлечения нефти наиболее широко применяется закачка растворов кислотных нефтевытесняющих композиций. Общей тенденцией является непрерывное совершенствование композиций, усложнение их состава и расширение спектра полезных функций. Наряду с индивидуальными кислотами начинают использовать комплексные кислоты, образующиеся в результате донорно-акцепторного взаимодействия компонентов композиции. Состав и свойства комплексных кислот регулируются концентрациями и соотношением донора и акцептора. Комплексные кислоты обладают поверхностно-активными свойствами, могут увеличивать нефтеотдачу низкопроницаемой матрицы пласта одновременно за счет растворения и капиллярной противоточной пропитки трещиновато-пористой породы.

В данной работе исследованы кислотные свойства комплексных кислот на основе борной кислоты и координационных растворителей - многоатомных спиртов (полиолов), таких как глицерин и сорбит. В системах неорганическая поликислота - полиол за счет донорноакцепторного взаимодействия образуются комплексные кислоты, намного более сильные,

$$
-365-
$$


чем исходная кислота $[2,3]$. Донорно-акцепторное взаимодействие усиливает кислотные свойства нефтевытесняющих композиций и увеличивает продолжительность их действия в пласте за счет повышения буферной емкости и расширения диапазона буферного действия в кислой области $\mathrm{pH}$. Донорно-акцепторное взаимодействие протекает в среде водного раствора полиола (многоатомного спирта) - глицерина и сорбита. Такой раствор является координирующим растворителем, полиол в нем - основание Льюиса, донор электронной пары. Растворенные в координирующем растворителе кислота Льюиса - борная кислота, - а также акваионы некоторых металлов: кальция, магния, железа и алюминия, - это акцепторы электронной пары донора. Химическая связь по типу донор - акцептор обладает свойствами поляризованной ковалентной связи и называется координационной или дативной связью. Взаимодействие донора и акцептора приводит к образованию молекулярного комплекса донор - акцептор, называемого координационным соединением или аддуктом. Комплекс намного более сильная кислота, чем исходная кислота Льюиса. Этот факт в России и за рубежом вызвал интерес к применению комплексных кислот в физико-химических технологиях повышения нефтеотдачи.

\section{Донорно-акцепторные равновесия в растворах}

Молекулы комплексной кислоты способны взаимодействовать с акваионами металлов за счет своих гидроксильных спиртовых групп. На рис. 1 приведена схема реакции, в которой отражена стереохимическая особенность молекулы глицеринборной кислоты - её способность образовывать растворимые внешнесферные циклические комплексы с ионами металлов за счет концевых гидроксильных групп. При увеличении концентрации акваионов металла в растворе, наряду с циклическими структурами, возможно образование полимероподобных ассоциатов, в которых акваионы металлов играют роль мостиков, связывающих молекулы комплексной кислоты в линейные и разветвленные пространственные ассоциативные структуры.

Как правило, такое структурообразование приводит к значительному возрастанию вязкости. Способ регулирования вязкости и плотности добавками солей указанных металлов может быть полезным для регулирования физико-химических и реологических свойств композиций. Кроме того, такое взаимодействие способствует совместимости комплексных кислот на основе полиолов с пластовыми водами, особенно с высокоминерализованными, с большим содержанием солей кальция и магния.

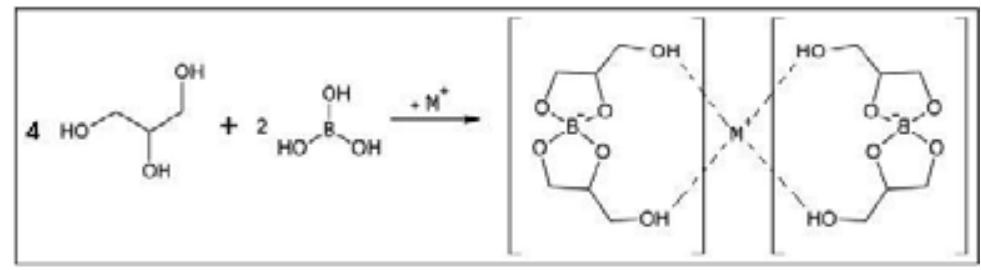

Рис. 1. Схема взаимодействия глицеринборной кислоты с катионом металла в растворе с образованием растворимого внешнесферного циклического комлекса

Fig. 1. Diagram of the glycerolboric acid interaction with a metal cation in solution with the formation of a soluble outer-sphere cyclic complex 
Количественной характеристикой донорно-акцепторных взаимодействий в растворах многоосновых кислот и полиолов являются константы комплексообразования и ионизации (диссоциации). Знание констант позволяет рассчитывать кислотность нефтевытесняющих композиций, их буферную емкость, прогнозировать и моделировать их поведение в пластовых условиях, в частности их взаимодействие с пластовой водой и породой-коллектором. Ниже кратко изложены теоретические аспекты расчетов констант образования и ионизации донорно-акцепторных комплексов многоосновных кислот с полиолами по экспериментальным данным, полученным

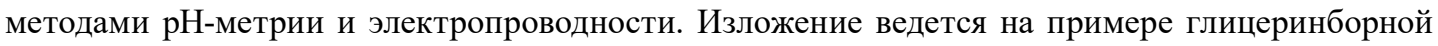
кислоты. Расчеты приведены для всех исследованных кислот и акваионов металлов.

Борная кислота при растворении в водно-глицериновом растворе практически мгновенно образует глицеринборную кислоту, диссоциирующую на ионы по типу одноосновной кислоты. В растворе устанавливается динамическое равновесие двух последовательных стехиометрических реакций:

- образование глицеринборной кислоты:

$$
\mathrm{H}_{3} \mathrm{BO}_{3}+2 \mathrm{C}_{3} \mathrm{H}_{8} \mathrm{O}_{3}=\mathrm{C}_{6} \mathrm{H}_{12} \mathrm{O}_{6} \mathrm{BH}+3 \mathrm{H}_{2} \mathrm{O}
$$

- ионизация, кислотная диссоциация глицеринборной кислоты:

$$
\mathrm{C}_{6} \mathrm{H}_{12} \mathrm{O}_{6} \mathrm{BH}=\mathrm{C}_{6} \mathrm{H}_{12} \mathrm{O}_{6} \mathrm{~B}^{-}+\mathrm{H}^{+} \text {. }
$$

В символьной форме эти реакции можно представить в виде

$$
\begin{aligned}
& \mathrm{HB}+2 \mathrm{G}=\mathrm{HBG}_{2}, \\
& \mathrm{HBG}_{2}=\mathrm{BG}_{2}^{-}+\mathrm{H}^{+},
\end{aligned}
$$

где $\mathrm{HB}$ - борная кислота, $\mathrm{G}$ - глицерин, $\mathrm{HBG}_{2}$ - глицеринборная кислота.

Формула для константы образования $\mathrm{K}_{\mathrm{c}}$ глицеринборной кислоты такова:

$$
K_{c}=\frac{\mathrm{c}_{\mathrm{hbg} 2}}{c_{h b} \cdot c_{g}^{2}}
$$

где $\mathrm{c}_{\mathrm{hbg} 2}$ - концентрация глицеринборной кислоты; $\mathrm{c}_{\mathrm{hb}}$ - концентрация борной кислоты; $\mathrm{c}_{\mathrm{g}}-$ концентрация глицерина.

Глицеринборная кислота в отличие от борной кислоты является кислотой средней силы, и так как концентрации аниона глицеринборной кислоты и катиона водорода равны, формула для константы ионизации $\mathrm{K}_{\mathrm{d}}$ глицеринборной кислоты имеет вид

$$
K_{d}=\frac{c_{b g 2}^{2}}{c_{h b g 2}} \text { или } K_{d}=\frac{c_{h}^{2}}{c_{h b g 2}}
$$

где $\mathrm{c}_{\mathrm{bg} 2}$ - концентрация аниона глицеринборной кислоты; $\mathrm{c}_{\mathrm{h}}$ - концентрация катиона водорода.

Уравнение материального баланса, учитывающее образование и ионизацию глицеринборной кислоты:

$$
\begin{aligned}
c_{h b 0}=c_{h b}+c_{h b g 2}+ & c_{b g 2}, \\
& -367-
\end{aligned}
$$


где $\mathrm{c}_{\mathrm{hb} 0}$ - стехиометрическая концентрация глицеринборной кислоты.

Концентрация анионов глицеринборной кислоты $\mathrm{c}_{\mathrm{bg} 2}$, являющейся органической кислотой, много меньше концентрации молекулярных форм. Поэтому уравнение материального баланса можно записать в виде

$$
c_{h b 0}=c_{h b}+c_{h b g 2}
$$

Совместное решение уравнений (1, 2 и 4) позволяет получить формулу, выражающую зависимость концентрации катионов водорода или анионов глицеринборной кислоты от концентраций борной кислоты и глицерина. Формула дает возможность рассчитать константы образования и ионизации глицеринборной кислоты на основании экспериментальных данных методов рН-метрии и электропроводности:

$$
h\left(c \cdot h b 0, c_{g 0}\right)=\sqrt{\frac{\mathrm{K}_{\mathrm{d}} \cdot \mathrm{K}_{\mathrm{c}} \cdot \mathrm{c}_{\mathrm{hb0}} \cdot \mathrm{c}_{\mathrm{g}}^{2}}{1+\mathrm{K}_{\mathrm{c}} \cdot \mathrm{c}_{\mathrm{hb} 0} \cdot \mathrm{c}_{\mathrm{g} 0}^{2}}} \text { или } b g 2\left(c_{h b 0}, c_{g 0}\right)=\sqrt{\frac{\mathrm{K}_{\mathrm{d}} \cdot \mathrm{K}_{\mathrm{c}} \cdot \mathrm{c}_{\mathrm{hb0}} \cdot c_{\mathrm{g} 0}^{2}}{1+\mathrm{K}_{\mathrm{c}} \cdot \mathrm{c}_{\mathrm{hbo}} \cdot \mathrm{c}_{\mathrm{g} 0}^{2}}} .
$$

Величина $\mathrm{pH}$ - это отрицательный десятичный логарифм концентрации ионов водорода:

$$
p H\left(c_{\cdot h b 0}, c_{g 0}\right)=-\log \left(h\left(c_{\cdot h b 0}, c_{g 0}\right)\right) .
$$

Логарифмируя уравнение (5) для концентрации ионов водорода, получим:

$$
p H\left(c \cdot h b 0, c_{g 0}\right)=-\frac{1}{2} \log \left(\sqrt{\frac{\mathrm{K}_{\mathrm{d}} \cdot \mathrm{K}_{\mathrm{c}} \cdot \mathrm{c}_{\mathrm{hb} 0} \cdot \mathrm{c}_{\mathrm{g} 0}^{2}}{1+\mathrm{K}_{\mathrm{c}} \cdot \mathrm{c}_{\mathrm{hb}} \cdot \mathrm{c}_{\mathrm{g} 0}^{2}}}\right) .
$$

В исследованиях методом электропроводности измеряли различные концентрационные зависимости удельной электропроводности (УЭП или к-греческая каппа) растворов. Теоретическую формулу, связывающую УЭП с константами образования и ионизации глицеринборной кислоты, можно получить на основании теории электролитов. Согласно теории, УЭП связана с эквивалентной электропроводностью $\lambda_{\mathrm{hbg} 2}$ глицеринборной кислоты формулой

$$
\kappa=\lambda_{h b g 2} \cdot c_{h b g 2}=\lambda_{h b g 2} \cdot \frac{c_{b g 2}}{v},
$$

где $v=2$ - стехиометрический коэффициент реакции ионизации глицеринборной кислоты.

Эквивалентная электропроводность глицеринборной кислоты равна сумме эквивалентных электропроводностей катиона водорода $\lambda_{\mathrm{h}}$ и аниона глицеринборной кислоты $\lambda_{\mathrm{bg} 2}$ :

$$
\lambda_{\text {hbg2 }}=\lambda_{h}+\lambda_{b g 2} .
$$

Эквивалентная электропроводность иона $\lambda_{\mathrm{i}}$ по правилу Вальдена - Писаржевского связана с вязкостью растворителя $\eta$ и радиусом гидратированного иона $r_{i}$ формулой вида

$$
\lambda_{i}=\frac{e_{0} \cdot N_{F}}{6 \cdot \pi \cdot \eta \cdot r_{\mathrm{i}}}
$$

где $\mathrm{e}_{0}$ - заряд электрона; $\mathrm{N}_{\mathrm{F}}-$ число Фарадея.

Комбинирование формул $(5,7-9)$ позволяет получить уравнение, связывающее экспериментальные значения УЭП и вязкости с константами образования и ионизации глицеринборной кислоты: 


$$
\kappa\left(c \cdot h b 0, c_{g 0}\right)=\sqrt{\frac{\mathrm{K}_{\mathrm{d}} \cdot \mathrm{K}_{\mathrm{c}} \cdot \mathrm{c}_{\mathrm{hb} 0} \cdot \mathrm{c}_{\mathrm{g} 0}^{2}}{1+\mathrm{K}_{\mathrm{c}} \cdot \mathrm{c}_{\mathrm{hb0}} \cdot \mathrm{c}_{\mathrm{g} 0}^{2}}} \cdot \frac{e_{0} \cdot N_{F}}{6 \cdot \pi \cdot \eta \cdot v} \cdot\left(\frac{1}{\mathrm{r}_{b g 2}}+\frac{1}{\mathrm{r}_{\mathrm{h}}}\right) .
$$

Радиус гидратированного катиона водорода $\mathrm{r}_{\mathrm{h}}=0.25$ нм рассчитан по формуле (9) с использованием справочного значения предельной эквивалентной электропроводности гидратированного иона водорода $\lambda_{\mathrm{i}}^{0}=330 \mathrm{~S}_{\mathrm{c}} \mathrm{cm}^{2} \cdot$ моль $^{-1}$ и вязкости $\eta=1$ мПасс при температуре $22{ }^{\circ} \mathrm{C}$ [4]. Радиус аниона глицеринборной кислоты рассчитан по формуле

$$
\mathrm{r}_{b g 2}=\sqrt[3]{\frac{m w_{g}}{\rho_{\mathrm{g}} \cdot N_{\mathrm{A}}}}=0.49 \mathrm{~nm}
$$

где $\mathrm{mw}_{\mathrm{g}}=92.1$ г/моль - молекулярная масса глицерина; $\rho_{\mathrm{g}}=1.26$ г $/ \mathrm{cm}^{3}$ - плотность глицерина; $\mathrm{N}_{\mathrm{A}}$ - число Авогадро. Расчет эффективного радиуса аниона является оценочным, в дальнейших исследованиях предполагается получить более точное значение путем измерения электрофоретической подвижности аниона методом капиллярного электрофореза. Следует отметить, что, согласно уравнению (10), чем больше эффективный радиус аниона по сравнению с радиусом гидратированного катиона водорода, тем меньше его влияние на значения УЭП.

\section{Материалы и методы}

Для проведения лабораторных исследований кислотно-основных равновесий в системах с донорно-акцепторными взаимодействиями: многоосновной неорганической борной кислоты и многоатомного спирта (глицерина и сорбита), готовили растворы борной кислоты с концентрациями 1,5 и $10 \%$ мас. в водно-спиртовых растворителях с концентрациями многоатомных спиртов от 10 до 70 \% мас. Использовали реактивы марки х.ч., ч.д.а. и дистиллированную воду. Определяли зависимость $\mathrm{pH}$, удельной электропроводности, вязкости и плотности растворов от концентрации компонентов. Значения $\mathrm{pH}$ растворов определяли потенциометрическим методом с использованием микропроцессорного лабораторного рН-метра производства HANNA Instruments, удельную электропроводность - с использованием кондуктометра АНИОН 4120, плотность - пикнометрическим методом. Вязкость растворов многоатомных спиртов определяли с помощью вибрационного вискозиметра «Реокинетика» с камертонным датчиком. Измерения проводили при температуре $20-23{ }^{\circ}$ C. Результаты исследований представлены на рис. 2-6 и в табл. 1.

\section{Результаты и обсуждение}

На рис. 2-5 приведены экспериментальные графики зависимостей $\mathrm{pH}$ и УЭП растворов от концентрации полиола при постоянной концентрации борной кислоты и рассчитанные по уравнениям (6) и (10). Графики на рис. 3, 5 демонстрируют сильное влияние вязкости растворителя на удельную электропроводность. В рамках теории неравновесных явлений в растворах электролитов это объясняется двояким влиянием полиола. С одной стороны, увеличение концентрации полиола приводит к возрастанию концентрации переносчиков электрического тока - анионов полиолборной кислоты и катионов водорода в соответствии с реакциями образования и ионизации кислоты. С другой стороны, увеличение концентрации полиола приводит к возрастанию вязкости, вызывающей торможение движения переносчи-

$$
-369-
$$




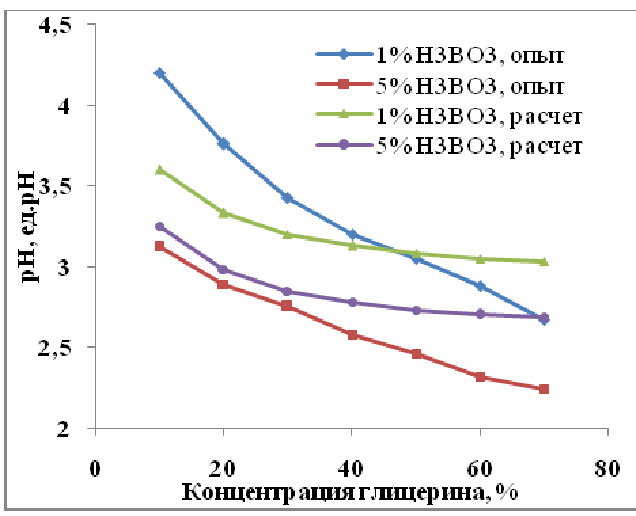

Рис. 2. $\mathrm{pH}$ растворов глицеринборной кислоты в зависимости от концентрации глицерина при постоянной концентрации борной кислоты

Fig. 2. Glycerolboric acid solutions $\mathrm{pH}$, depending on the concentration of glycerol at a constant concentration of boric acid

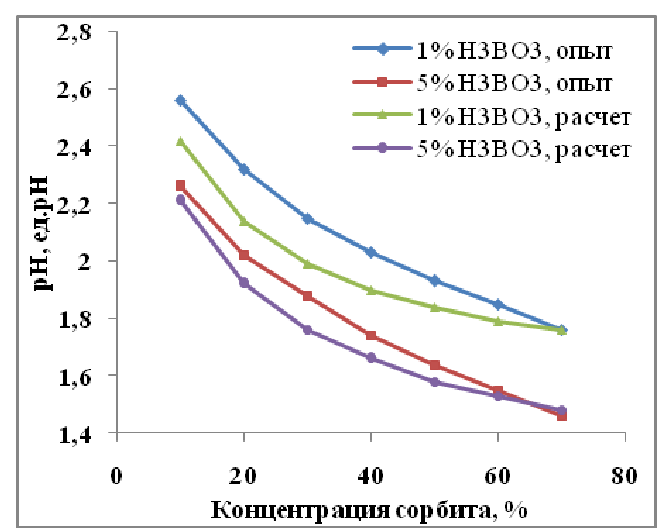

Рис. 4. $\mathrm{pH}$ растворов сорбитборной кислоты в зависимости от концентрации сорбита при постоянной концентрации борной кислоты

Fig. 4. Sorbitolboric acid solutions $\mathrm{pH}$, depending on the concentration of sorbitol at a constant concentration of boric acid

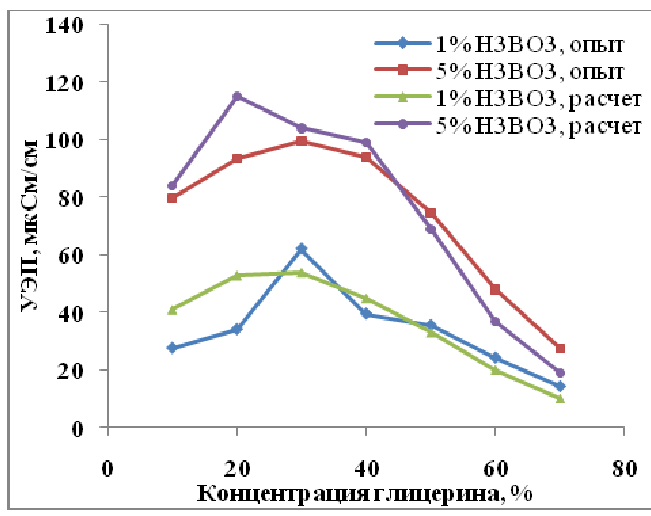

Рис. 3. Удельная электропроводность растворов глицеринборной кислоты в зависимости от концентрации глицерина при постоянной концентрации борной кислоты

Fig. 3. Specific conductivity of glycerolboric acid solutions, depending on the glycerol concentration at a constant boric acid concentration

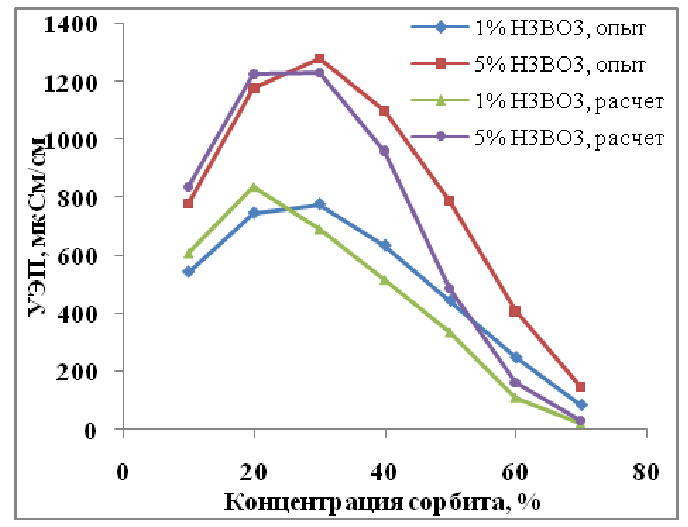

Рис. 5. Удельная электропроводность растворов сорбитборной кислоты в зависимости от концентрации сорбита при постоянной концентрации борной кислоты

Fig. 5. Specific conductivity of sorbitolboric acid solutions, depending on the sorbitol concentration at a constant boric acid concentration

ков тока и, тем самым, к уменьшению УЭП. Вначале доминирует процесс образования переносчиков тока, затем, после точки экстремума, главным фактором становится вязкостное торможение. Экстремум УЭП находится в интервале концентрации 25-35 \% мас. глицерина и сорбита.

На рис. 2, 4 видно, что уменьшение $\mathrm{pH}$ с увеличеним концентрации полиола носит монотонный характер. Это обусловлено непрерывным сдвигом равновесия реакции ионизации, сопряженным со сдвигом реакции образования комплекса борной кислоты с полиолом. 
Таблица 1. Концентрационные константы образования и ионизации глицеринборной и сорбитборной кислот в полиольном координирующем растворителе

Table 1. Concentration constants of glycerolboric and sorbitolboric acids formation and ionization in a polyol coordinating solvent

\begin{tabular}{|c|c|c|}
\hline Кислота & $\mathrm{K}_{\mathrm{c}}$, л $^{2} \cdot$ моль $^{-2}$ & $\mathrm{~K}_{\mathrm{d}}$, моль·л $^{-1}$ \\
\hline Глицеринборная & 0.05 & $7.1 \cdot 10^{-6}$ \\
\hline Сорбитборная & 0.06 & $3.2 \cdot 10^{-3}$ \\
\hline
\end{tabular}

Экстремальный характер концентрационных зависимостей для УЭП и монотонный для pH указывает на изменения в структуре координирующего растворителя, начиная с 30 \% мас. полиола.

Согласованная обработка экспериментальных концентрационных зависимостей рН и удельной электропроводности растворов глицеринборной и сорбитборной кислот по уравнениям (6) и (10) позволила получить значения констант образования и ионизации глицеринборной и сорбитборной кислот в полиольном координирующем растворителе (табл. 1).

Как видим, сорбитборная кислота значительно сильнее глицеринборной. Поэтому представляет интерес совместное использование глицерина и сорбита в нефтевытесняющих композициях.

Полученные значения констант были использованы для расчета буферной емкости композиций. Буферная емкость - это количества кислоты или щелочи, при добавлении которых рН буферного раствора изменяется на единицу. Чем выше буферная емкость, тем сильнее раствор сопротивляется изменению своего $\mathrm{pH}$ при добавлении кислот, щелочей или при разбавлении. Для буферной системы, состоящей из полиолборной кислоты и её соли, аналитическое выражение для буферной емкости $\beta$ имеет вид

$$
\beta\left(p H, c_{a}\right)=2.303 \cdot\left(\frac{\mathrm{K}_{\mathrm{a}} \cdot \mathrm{c}_{\mathrm{a}} \cdot 10^{-\mathrm{pH}}}{\left(\mathrm{K}_{\mathrm{a}}+10^{-\mathrm{pH}}\right)^{2}}+10^{-\mathrm{pH}}+\frac{10^{-\mathrm{pK}} \mathrm{w}}{10^{-\mathrm{pH}}}\right),
$$

где $\mathrm{pH}$ - водородный показатель; $\mathrm{c}_{\mathrm{a}}$ - концентрация кислоты; $\mathrm{K}_{\mathrm{a}}-$ константа диссоциации кислоты, $\mathrm{pK}_{\mathrm{w}}$ - ионное произведение воды.

На рис. 6 приведены графики буферной емкости систем из глицеринборной и сорбитборной кислот по отдельности и в смеси друг с другом в зависимости от $\mathrm{pH}$. Графики рассчитаны по уравнению (12).

Как видим на рис. 6, диапазон буферного действия смеси кислот является суммой диапазонов систем индивидуальных кислот. Это обстоятельство дает возможность регулировать диапазон буферного действия путем использования в композициях смеси полиолборных кислот в различных соотношениях.

\section{Заключение}

Создана теоретическая модель донорно-акцепторных кислотно-основных равновесий в координирующих полиольных растворителях, позволившая определить константы образования и ионизации полиолборных кислот методами $\mathrm{pH}$-метрии и электропроводности. Полученные 


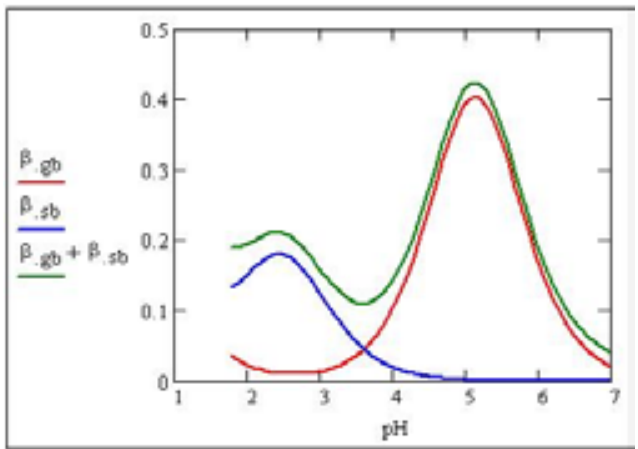

Рис. 6. Буферная емкость растворов глицеринборной $\left(\beta_{\mathrm{gb}}\right)$, сорбитборной $(\beta \mathrm{sb})$ кислот и раствора их смеси в соотношении 7:3 $\left(\beta_{\mathrm{gb}}+\beta_{\mathrm{sb}}\right)$

Fig. 6. Buffer capacity of glycerinboric $\left(\beta_{\mathrm{gb}}\right)$ and sorbitolboric $\left(\beta_{\mathrm{sb}}\right)$ acid solutions and that of their mixture solution at the ratio $7: 3\left(\beta_{\mathrm{gb}}+\beta_{\mathrm{sb}}\right)$

значения констант были использованы для расчета буферной емкости композиций. Показана возможность регулирования диапазона буферного действия путем применения в композициях смеси полиолборных кислот в различных соотношениях. Согласие экспериментальных данных с результатами расчетов с использованием теоретической модели указывает на перспективность разработки нефтевытесняющих кислотных композиций на основе ПАВ, координирующих растворителей и комплексных соединений с целью интенсификации разработки и увеличения нефтеотдачи месторождений тяжелой высоковязкой нефти.

Работа выполнена при финансовой поддержке Министерства науки и высшего образования Российской Федерации в рамках ФЦП «Исследования и разработки по приоритетным направлениям развития научно-технологического комплекса России на 2014-2020 годы" по приоритетному направлению "Рациональное природопользование», Соглашение о предоставлении субсидии №14.604.21.0176 от 26.09.2017, уникальный идентификатор RFMEFI60417Х0176. Результаты работ получены с использованием научного оборудования Томского регионального центра коллективного пользования ТНЦ СО РАН, Федерального государственного бюджетного учреждения науки Института химии нефти Сибирского отделения Российской академии наук.

\section{Список литературы}

1. Алтунина Л.К., Кувшинов В.А., Кувшинов И.В., Стасьева Л.А., Чертенков М.В., Шкрабюк Л.С., Андреев Д.В. Физико-химические и комплексные технологии увеличения нефтеотдачи пермо-карбоновой залежи высоковязкой нефти Усинского месторождения. Нефтяное хозяйство 2017. № 7. C. 26-29 [Altunina L.K., Kuvshinov V.A., Kuvshinov I.V., Stasyeva L.A., Chertenkov M.V., Shkrabyuk L.S., Andreev D.V. Physical-chemical and complex EOR/IOR technologies for the Permian-Carboniferous deposit of heavy oil of the Usinskoye oil field. Oil Industry 2017. No. 7. P. 26-29 (In Russ.)]

2. Shvarts E.M., Ignash R.T., Belousova R.G. Reactions of Polyols with Boric Acid and Sodium Monoborate. Russian Journal of General Chemistry. 2005. Vol. 75(11). 1687-1692. 
3. Троицкий Г.В., Ажицкий Г.Ю. Изоэлектрическое фокусирование белков в боратглицериновом рН-градиенте. Киев: Наукова думка, 1984. 220 с. [Troitsky G.V., Azhitsky G.Yu. Isoelectric focusing of proteins in borate-glycerin pH gradient. Kiev, Naukova Dumka, 1984. 220 p. (In Russ.)]

4. Справочник по электрохимии. Под ред. А.М. Сухотина. Л.: Химия, 1981. 488 с. [Handbook of Electrochemistry. Ed. A.M. Sukhotina. L., Chemistry, 1981. 488 p. (In Russ.)] 